\title{
BMJ Open A comparative assessment of the price, brands and pack characteristics of illicitly traded cigarettes in five cities and towns in South Africa
}

\author{
Anna E Wherry, ${ }^{1}$ Cheyenne A McCray, ${ }^{1}$ Temidayo I Adedeji-Fajobi, ${ }^{1}$ Xolani Sibiya, ${ }^{2}$ \\ Peter Ucko, ${ }^{3}$ Limakatso Lebina, ${ }^{2}$ Jonathan E Golub, ${ }^{4}$ Joanna E Cohen, ${ }^{5,6}$ \\ Neil A Martinson ${ }^{2,6}$
}

To cite: Wherry $A E$, McCray CA, Adedeji-Fajobi TI, et al. A comparative assessment of the price, brands and pack characteristics of illicitly traded cigarettes in five cities and towns in South Africa. BMJ Open 2014;4: e004562. doi:10.1136/ bmjopen-2013-004562

- Prepublication history for this paper is available online. To view these files please visit the journal online (http://dx.doi.org/10.1136/ bmjopen-2013-004562).

Received 15 December 2013 Revised 8 April 2014 Accepted 10 April 2014

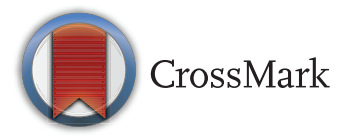

For numbered affiliations see end of article.

Correspondence to Dr Neil A Martinson; martinson@phru.co.za

\section{ABSTRACT}

Objective: The prevalence of illicitly traded cigarettes in South Africa has been reported to be $40-50 \%$. However, these estimates do not account for the more nuanced characteristics of the illicit cigarette trade. With the goal of better understanding contraband cigarettes in South Africa, this study piloted three methods for assessing the price, brands, pack features and smoker's views about illicit cigarettes in five cities/ towns. Data were collected in June and July 2012.

Setting: A convenience sample of three South African cities (Johannesburg, Durban and Nelspruit) and two smaller towns (Musina and Ficksburg) were chosen for this study.

Outcome measures: Three cross-sectional approaches were used to assess the characteristics of contraband cigarettes: (1) a dummy purchase of cigarettes from informal retailers, (2) the collection of discarded cigarette packs and (3) a survey of tobacco smokers.

Participants: For the purposes of the survey, 40 selfreported smokers were recruited at taxi ranks in each downtown site. Adults who were over the age of 18 were asked to verbally consent to participate in the study and answer a questionnaire administered by a researcher.

Results: The leading reason for labelling a pack as illicit in each city/town was the absence of an excise stamp ( $28.6 \%$ overall), and the least common reason was an illegal tar or nicotine level ( $11.1 \%$ overall). The overall proportion of informal vendors who sold illicit cigarettes was $41 \%$. Singles and packs of 20 were consistently cheaper at informal vendors. Survey participants' responses reflected varied perspectives on illicit cigarettes and purchasing preferences.

Conclusions: Each approach generated an interesting insight into physical aspects of illicit cigarettes. While this pilot study cannot be used to generate generalisable statistics on illicit cigarettes, more systematic surveys of this nature could inform researchers' and practitioners' initiatives to combat illicit and legal cigarette sales and usage.

\section{Strengths and limitations of this study}

- The three methods required little time and resources to conduct.

- The dummy purchase of cigarettes offered a beneficial understanding of local channels of availability, specifically through spaza shops and street vendors.

- The collection of discarded cigarette packs provided insight into the distribution of illicitly traded brands in the different sample locations.

- The consumer survey provided anecdotal accounts of smokers' perceptions regarding illicitly traded cigarettes, such as how they were perceived to cause more severe cough.

- As the pilot study is restricted to only small, non-randomly selected sites, the data must be understood as being illustrative of five specific microeconomies and social networks. The data thus cannot be considered representative of South Africa as a whole, nor used to make countrywide inferences.

- The selection of study sites lead to demographic specificity; the respondents to our smokers' survey were almost all black men, and are not representative of either the smoking or overall population of South Africa.

- The survey was restricted to informal businesses and does not capture data on volumes of sales, or of the sale of illicitly traded cigarettes by formal vendors of tobacco products in South Africa.

- Both researchers and respondents may not have always correctly categorised illicitly traded cigarettes by price and packaging-especially those illicit packages that might have expertly mimicked legal packaging requirements.

- Some survey respondents were reluctant to respond to questions specifically dealing with illicitly traded cigarettes and some potential respondents who denied smoking were subsequently seen to be smoking. 


\section{BACKGROUND}

The widespread availability of cheaper contraband or illicit cigarettes in South Africa has been touted to undermine national tax efforts to reduce smoking through increasing the price the consumer pays for tobacco products. ${ }^{1-6}$ The WHO Framework Convention on Tobacco Control (FCTC) includes provisions to address illicit trade in tobacco products, and in November 2012 the delegates of more than 140 parties to the FCTC adopted a new international protocol for combating illicit trade. ${ }^{7}$ Illicit trade in tobacco products is defined in Article 1 of FCTC as "any practice or conduct prohibited by law and which relates to production, shipment, receipt, possession, distribution, sale or purchase including any practice or conduct intended to facilitate such activity."

There are concerns that recent gains in tobacco control in South Africa may be reduced or even counteracted due to the illicit trade of cigarettes from neighbouring countries. ${ }^{9}$ News reports describing cigarette 'runners' crossing the Zimbabwe border-the sixth largest tobacco exporter globally ${ }^{10}$ - suggest that they carry an average of ZAR 12900 ( $\sim$ US\$1300) worth of illicitly traded cigarettes per run. ${ }^{11-13}$ These reports have been utilised by the South African tobacco industry to argue against further increases in excise taxes, ${ }^{14}$ using advertising campaigns against the purchase of illicit cigarettes. ${ }^{15}$ Tobacco company funded research suggests that 19 million cigarettes are sold illegally every day, amounting to an estimated illicit cigarette prevalence of $40-50 \%$ in South Africa. ${ }^{16}$

Currently, there is little known beyond these statistics regarding the characteristics of illicitly traded cigarettes. In this pilot study, we implemented and compared three methods that evaluate price, types of cigarettes, pack features and smoker's perceptions of illicit cigarettes in five locations in South Africa.

\section{METHODS}

Criteria for categorising cigarette packs into 'likely illicitly traded cigarettes' and 'legal' were based on the 1993 South African Tobacco Products Control Act $83,{ }^{17}$ which stipulates that packs must have a visible South African excise stamp; correct and corresponding health warning labels must be appropriately sized and placed on the front and back of the pack (there are 8 allowed labelling messages); the South African smoking information telephone number (the National Quit Line: +27117203145) must be printed on the back of the pack; and tar and nicotine content must not exceed 12 and $1.2 \mathrm{mg}$, respectively. ${ }^{17}$ Given the excise tax on cigarettes in South Africa, the selling price of single cigarettes and a pack of 20 cigarettes must be at least ZAR $1.5(\sim \mathrm{US} \$ 0.15)$ and ZAR 13.50 ( US\$1.36), respectively. ${ }^{17}$

Three approaches were selected and piloted after discussions with local experts in tobacco control, and after investigating the feasibility of implementation. None of the methods in this study required the purchase of tobacco products.

\section{Dummy purchase of cigarettes from informal vendors}

Two groups of informal cigarette vendors were included: (1) hawkers or street vendors located close to large taxi ranks and (2) microenterprises or 'spaza shops', which are small grocery stores usually located in the yard or house of a private dwelling in large townships or dormitory towns serving the city of each study site. Spaza shops and street vendors are informal businesses operating with little regulatory oversight and may be more likely to sell illicitly traded goods than a formal supermarket or shop. Street vendors displayed most of what they had for sale in open sight on tables that lined curbsides of streets, allowing customers to browse easily. Spaza shops kept what they had for sale behind glass windows and conducted business through open windows. Their informal quality thus provides an opportunity to observe how contraband cigarettes are traded and sold. The dummy cigarette purchases were also designed to ascertain the price of legal and potentially illicitly traded brands of cigarettes sold on the streets in the city centre (for street vendors) and within residential areas (for spaza shops).

Twenty street vendors and 10 spaza shops were surveyed in each city/town. Data were not collected from those vendors nearest to immigration or customs officials to avoid potential legal problems. Two researchers conducted each dummy cigarette purchase; one asked for cigarettes while the other reviewed the different brands available. Based on the brands observed and prices given, if no illicitly traded cigarettes were perceived to be offered for sale, the team would ask the vendor for a cheaper cigarette for less than ZAR 2.00 ( $\sim$ US $\$ 0.24$ ). Cigarette packaging was observed for legislative requirements to ascertain legality. After examining each brand and determining the cheapest legal and the cheapest illicitly traded cigarette, if available, the researchers would depart and immediately complete a case report form which included: presence of cigarettes in packs of 10 , packs of 20 or as singles; whether or not illicitly traded cigarettes were observed to be available for purchase; the price of the cheapest legal and cheapest illicitly traded cigarettes, if available, sold in packs of 10, packs of 20 and as singles. Spaza shop visits followed a similar pattern of data collection, except that it was necessary to drive around the local township until a spaza shop was found. Additionally, in spaza shops, the team recorded the presence or absence of legally required signs prohibiting the sale of cigarettes to individuals younger than 18 years.

\section{Discarded cigarette packs}

At least 100 discarded cigarette packs were collected per city/town. The packs collected were found in refuse bins or as litter picked up from sidewalks and gutters, on both sides of the street, within five city blocks of a large 
taxi rank in each downtown site. The final number of blocks or total length of streets where packs were collected depended on the local street layout and perceived safety of the team. Any visible empty cigarette packs that were not soiled and had legible writing were collected. Gloves were used to pick up the cigarette packs which were placed in sealed, labelled bags. The collected discarded cigarette packs were later categorised according to the study definitions (see pg. 2) as illicitly traded or legal.

\section{Smokers survey}

Forty self-reported smokers were recruited at taxi ranks in each downtown site. Adults aged 18 and over were approached and asked if they were smokers. All individuals who reported smoking were asked to verbally consent to participate in the study and answer a questionnaire administered by a researcher. The survey contained basic demographic questions: questions regarding smoking behaviours, as well as questions to ascertain the use of illicitly traded cigarettes, such as brands usually smoked and prices paid for packs of cigarettes and single cigarettes. Participants were also asked if the user ever purchased contraband cigarettes. Finally, participants were asked how they were able to distinguish between legal and contraband cigarettes, and were provided the opportunity to share their personal views on contraband cigarettes. Contraband cigarettes were defined as cigarettes that the participant believed to be illegal or 'fongkong', a colloquial term referring to cigarettes traded illicitly. Surveys were conducted in the language of choice of the respondent, and took approximately $10 \mathrm{~min}$ to complete. Two hundred surveys were completed, 40 in each city/town. After the survey was completed, participants were provided with smoking cessation information if requested.

\section{Study sites}

A convenience sample of towns and cities was selected for this pilot study. Three South African cities (Johannesburg, Durban and Nelspruit) and two smaller towns (Musina and Ficksburg) were chosen. The locations were selected for their quality as potential 'hot spots' for illicit cigarette trade, ensuring the presence of ample cigarette vendors and pedestrian traffic. The localities we selected and their local taxi ranks represent specific microeconomies and therefore cannot be considered representative of the entire city/town, let alone South Africa as a whole. ${ }^{8}$

Three of the sites (Nelspruit, Ficksburg and Musina) were specifically selected for their proximity to countries neighbouring South Africa. Each city's or town's largest minibus taxi rank was chosen as the primary hub of the survey due to the universal use of taxi transport by commuters in South Africa. Areas adjacent to taxi ranks in cities and towns in South Africa have a predictably high volume of pedestrian traffic accessing taxi ranks as well as a high density of informal street vendors selling to commuters. Nelspruit was selected due to its proximity to both Swaziland and Mozambique. Nelspruit's taxi rank, located on Andrew Street, was used for the study, and spaza shop vendors were selected from the largest residential township in Nelspruit: Kanyamazane. Musina was selected due to its proximity to Zimbabwe, the sixth largest tobacco leaf exporter in the world..$^{10}$ The taxi rank is located on N1 highway and data collection for the spaza shop vendors was conducted in two of the largest neighbouring residential townships in Musina: Freedompark and Niceville. Two townships were used in Musina due to its relatively smaller residential areas in comparison to the other townships in the study. Ficksburg is located on the border with Lesotho. The taxi rank on Bloem St is about $200 \mathrm{~m}$ from and within eyesight of the South African border control post. Data collection for the spaza shop vendors was conducted in the largest residential township in Ficksburg: Meqheleng. Durban is the largest seaport serving southern Africa. Cross Street taxi rank was selected for surveys of smokers and of street vendors. The township of Phoenix was selected to identify spaza shops. Johannesburg is the economic hub of South Africa. The Noord Street taxi rank in downtown Johannesburg was selected to identify smokers and street vendors, and the survey of spaza shop vendors was conducted in Soweto, South Africa's largest residential township. Data collection was conducted in June and July 2012. Each city/town required 3-4 days to complete study procedures except that in Ficksburg, owing to its size and ease of interviews, it was completed in just 1 day.

\section{Analysis}

Data were stratified by locality and subsequently used to determine the characteristics of illicitly traded cigarettes presented by each methodology. Specifically, the analysis isolated data on: the average prices of contraband cigarettes versus legal cigarettes, the distribution of contraband and legal brands by location, the reasons for classifying a discarded cigarette pack as illicitly traded, the proportion of collected discarded cigarette boxes classified as likely contraband, the proportion of sample vendors selling illicitly traded cigarettes and the proportion of survey participants who reported ever purchasing contraband cigarettes. Epi Info 7 and R statistical tool software were used to analyse the data.

\section{RESULTS}

Data collection was from June to July 2012. The team did not encounter problems while implementing any of the study procedures. In the following section, the results are presented according to the methodology described earlier.

\section{Dummy purchase of cigarettes from informal vendors}

In Johannesburg, Durban and Nelspruit, vendors appeared to freely provide data on price and sales of 
Table 1 Proportion of spaza shops and street vendors selling illicitly traded cigarettes

\begin{tabular}{lllllll}
\hline & Johannesburg & Durban & Nelspruit & Musina & Ficksburg & Total \\
\hline Spaza shop & $n=10 ; 70 \%$ & $n=10 ; 60 \%$ & $n=10 ; 70 \%$ & $n=10 ; 20 \%$ & $n=10 ; 50 \%$ & $n=50 ; 54 \%$ \\
Street vendor & $n=20 ; 70 \%$ & $n=20 ; 30 \%$ & $n=20 ; 80 \%$ & $n=20 ; 25 \%$ & $n=20 ; 0 \%$ & $n=100 ; 41 \%$ \\
Total & $n=30 ; 70 \%$ & $n=30 ; 40 \%$ & $n=30 ; 77 \%$ & $n=30 ; 23 \%$ & $n=30 ; 23 \%$ & $n=150 ; 45 \%$ \\
\hline
\end{tabular}

illicitly traded cigarettes. However, Musina and Ficksburg were characterised by a reluctance to offer illicit cigarettes. For instance, when asked, many street vendors in Musina said, 'go to Zimbabwe.' Overall, the proportion of street vendors who sold illicitly traded cigarettes was $41 \%$ with a range from $80 \%$ in Nelspruit to $0 \%$ in Ficksburg (table 1). Over half $(54 \%)$ of the spaza shops sold illicitly traded cigarettes with a range of $70 \%$ in Nelspruit and Johannesburg to $20 \%$ in Musina.

The average retail price of a box of the cheapest 20 'legal' cigarettes was ZAR 30.79 at spaza shops and ZAR 28.00 at street vendors, whereas the average price of the cheapest illicitly traded packs of 20 cigarettes was ZAR 16.31 and ZAR 13.78 at spaza shops and street vendors, respectively (table 2). Similarly 'legal' singles retailed at ZAR 1.99 and ZAR 2.13 at spaza shops and street vendors, respectively, whereas illicitly traded singles typically retailed at ZAR 0.95 and ZAR 0.93 (table 2). Only $16.3 \%$ of spaza shops displayed government warnings prohibiting the sale of cigarettes to minors and $10 \%$ possessed formal advertising stands for cigarettes. No counterfeit packages of established legal brands were observed, although it is possible that illicit packages for these brands successfully reproduced all legal criteria.

\section{Collection of discarded cigarette packs}

Of 558 packs collected from streets, trash piles, bins and gutters, 147 were determined to be illicit $(26.3 \%$; $95 \%$ CI $22.8 \%$ to $30.2 \%$ ). The city/town with the highest proportion of discarded illicitly traded cigarettes at the sample sites was Musina ( $56.3 \%$ of all boxes collected) and the site with the lowest proportion was Ficksburg (2.4\% of all boxes collected).

The top five brands of discarded cigarette packs categorised as illicit according to study definitions were Remington Gold (43), Safari (29), Dullahs (18), Pacific Blue (16) and Aspen (11; table 3). The frequency of illicit brands varied greatly by city/town.
Overall, the leading reasons for classifying a discarded cigarette pack as illicit in descending order were: absence of an excise stamp (28.6\%), incorrect or missing health warnings $(26.9 \%)$, absence of the National Quit Line number $(25.9 \%)$, tar or nicotine level that was missing or higher than allowed (13.6\% and $11.1 \%$, respectively). At least one of these criteria was inadequate or missing in $28.6 \%$ of the discarded cigarette packs.

\section{Smokers survey}

Almost all $(98.5 \%)$ survey participants identified as male and virtually all (97.5\%) identified as black South African. The median number of cigarettes smoked was 14/day. Most respondents $(72.1 \%)$ reported that they usually purchased single cigarettes. In total, $71.1 \%$ reported only purchasing legal cigarettes, whereas $27.4 \%$ reported purchasing both legal and illicitly traded cigarettes and $1.5 \%$ reported exclusively purchasing illicitly traded cigarettes. Participants reported paying an average of ZAR 2.20 for single cigarettes and ZAR 26.6.

The most frequently reported illicitly traded cigarettes purchased by participants were Madison (11 reports) and Remington Gold (10 reports). Respondents were asked to describe how they distinguished a 'fongkong' or contraband cigarette from a legal cigarette. The three most commonly reported explanations were due to 'fongkong' cigarettes having adverse effects on the body, such as causing cough (38); differences in taste (30) and physical differences in the cigarette or packaging (27). Branding was also reported as an indicator of contraband 15 times. Several participants (14) reported not knowing how to distinguish between contraband and legal cigarettes.

\section{DISCUSSION}

This pilot study utilised three methods to investigate the characteristics of illicitly traded cigarettes in five "hot

Table 2 Average retail price of cheapest legal versus cheapest illicitly traded single cigarettes and packs of 20 at spaza shops and street vendors

\section{Single cigarettes}

\begin{tabular}{lllllll}
\hline & Johannesburg & Durban & Nelspruit & Musina & Ficksburg & Total \\
\hline Legal & ZAR 1.90 & ZAR 1.97 & ZAR 2.00 & ZAR 2.31 & ZAR 2.26 & ZAR 2.08 \\
$\begin{array}{l}\text { Illicitly traded } \\
\text { Packs of 20 }\end{array}$ & ZAR 0.85 & ZAR 0.96 & ZAR 1.08 & ZAR 0.6 & ZAR 1.06 & ZAR 0.93 \\
Legal & ZAR 30.53 & ZAR 27.71 & ZAR 25.05 & ZAR 31.25 & ZAR 29.00 & ZAR 29.34 \\
Illicitly traded & ZAR 15.15 & ZAR 13.8 & ZAR 15.42 & ZAR 11.00 & ZAR 18.83 & ZAR 14.82 \\
\hline
\end{tabular}


Table 3 Most frequently discarded illicitly traded brands, by city/town

\begin{tabular}{|c|c|c|c|}
\hline Brand & Number & $\begin{array}{l}\text { Proportion among illicitly } \\
\text { traded cigarettes (\%) }\end{array}$ & $\begin{array}{l}\text { Proportion among all } \\
\text { cigarettes collected (\%) }\end{array}$ \\
\hline \multicolumn{4}{|l|}{ Johannesburg } \\
\hline Dullahs & 16 & 43 & 14 \\
\hline Remington Gold & 9 & 24 & 8 \\
\hline Grande Turismo & 4 & 11 & 3 \\
\hline Mega 20 & 4 & 11 & 3 \\
\hline Kingsgate & 2 & 5 & 2 \\
\hline Pacific Blue & 2 & 5 & 2 \\
\hline \multicolumn{4}{|l|}{ Durban } \\
\hline Pacific Blue & 13 & 46 & 10 \\
\hline Aspen & 11 & 39 & 9 \\
\hline Mega 20 & 2 & 7 & 1 \\
\hline Pall Mall & 1 & 4 & 1 \\
\hline Ransom & 1 & 4 & 1 \\
\hline \multicolumn{4}{|l|}{ Nelspruit } \\
\hline Safari & 29 & 97 & 29 \\
\hline Pall Mall & 1 & 3 & 1 \\
\hline \multicolumn{4}{|l|}{ Musina } \\
\hline Remington Gold & 34 & 69 & 39 \\
\hline Madison & 10 & 20 & 12 \\
\hline Dullahs & 2 & 4 & 2 \\
\hline Everest & 1 & 2 & 1 \\
\hline Marlboro & 1 & 2 & 1 \\
\hline Mega 20 & 1 & 2 & 1 \\
\hline \multicolumn{4}{|l|}{ Ficksburg } \\
\hline Pacific Blue & 1 & 33 & 1 \\
\hline Pall Mall & 1 & 33 & 1 \\
\hline Sasha & 1 & 33 & 1 \\
\hline
\end{tabular}

spot' locations across South Africa. Specifically, information was generated on differences in pricing, types of brands, characteristics of illicit packaging and perceptions on the use of contraband cigarettes among smokers.

As the pilot study is restricted to only small, nonrandomly selected sites, the data must be understood as illustrative of five specific microeconomies and social networks. The data thus cannot be considered representative of South Africa as a whole, nor used to make countrywide inferences. The selection of study sites also led to demographic specificity; the respondents to our smokers' survey were almost all black men, and are not representative of either the smoking or overall population of South Africa. An additional consideration is that researchers and respondents may not have always correctly categorised illicitly traded cigarettes by price and packaging-especially those illicit packages that might have expertly mimicked legal packaging requirements. The survey was also restricted to informal businesses and does not capture data on volumes of sales, or of the sale of illicitly traded cigarettes by formal vendors of tobacco products in South Africa. Moreover, some survey respondents were reluctant to respond to questions specifically dealing with illicitly traded cigarettes and some potential respondents who denied smoking were subsequently seen to be smoking. Finally, use of colloquial terms for illicitly traded cigarettes differed by study site and researchers may not have understood or used the appropriate local colloquial term for illicitly traded cigarettes when administering the survey questionnaire.

Despite these limitations, the three methods we report required little time and resources to conduct. If future research is successful at using one of these methods to conduct a geographically representative study, governments may also consider conducting such independent studies as a cost-effective and time-sensitive alternative to industry estimates. The dummy purchase of cigarettes offered a beneficial understanding of local channels of availability, specifically through spaza shops and street vendors. The collection of discarded cigarette packs provided insight into the distribution of illicitly traded brands in the different sample locations. This method, however, is limited by a small sample size and the inability to confirm the original place of purchase. Our consumer survey provided anecdotal accounts of smokers' perceptions regarding illicitly traded cigarettes, such as how they were perceived to cause more severe cough. The surveys also provided information on prices paid for 'fongkong' cigarettes by city.

Illicit cigarettes were clearly found in all the sample sites we selected. Although we cannot report on the 
overall prevalence of either use or sale of contraband cigarettes, our study formally demonstrates that: there is a significant difference in pricing of illicit and legal cigarettes (average cost difference of ZAR 11.69 ( US $\$ 1.19$ ) between a legal vs an illicitly traded pack of 20 sold at a street vendor); that cartons of illicitly traded cigarettes collected are most commonly characterised by the lack of an excise stamp (28.6\% overall); and that illicitly traded cigarette brands are not uniform across the country.

\section{Author affiliations}

${ }^{1}$ Kreiger School of Arts and Sciences, Johns Hopkins University, Baltimore, Maryland, USA

${ }^{2}$ Perinatal HIV Research Unit, University of the Witwatersrand, Johannesburg, South Africa

${ }^{3}$ National Council against Smoking, Johannesburg, South Africa

${ }^{4}$ Johns Hopkins University School of Medicine, Center for Tuberculosis Research, Baltimore, Maryland, USA

${ }^{5}$ Department of Health, Behavior and Society, Johns Hopkins University Bloomberg School of Public Health, Baltimore, Maryland, USA

${ }^{6}$ Institute for Global Tobacco Control, Johns Hopkins Bloomberg School of Public Health, Baltimore, Maryland, USA

Acknowledgements The authors would like to thank Ms Charity Leeuw and Ms Sandy Chon who provided invaluable support to the study team, and Dr Yusuf Saloojee who gave valuable advice.

Contributors AEW, CAM and TIA-F contributed to the design, conception, acquisition, analysis and interpretation of the project and data; the drafting and revision of the manuscript and the approval of the final version to be published. XS contributed to the acquisition of data. PU contributed to the design and conception of the project. LL contributed to the revision of the manuscript and the conception of the project. JEC contributed to the drafting and revision of the manuscript and the approval of the final version to be published. JEG and NAM contributed to the design and conception of the project; the drafting and revision of the manuscript and the approval of the final version to be published.

Funding This study was supported by the Institute for Global Tobacco Control with funds from the Bloomberg Initiative to Reduce Tobacco Use and the Johns Hopkins Center for Global Health.

Competing interests JEG and NAM are partially supported by a grant from the National Institute on Drug Abuse (R01 DA030276).

Patient consent Obtained.

Ethics approval Institutional review boards of the Johns Hopkins University and the University of the Witwatersrand approved the survey of self-reported smokers.

Provenance and peer review Not commissioned; externally peer reviewed.

Data sharing statement No additional data are available.
Open Access This is an Open Access article distributed in accordance with the Creative Commons Attribution Non Commercial (CC BY-NC 3.0) license, which permits others to distribute, remix, adapt, build upon this work noncommercially, and license their derivative works on different terms, provided the original work is properly cited and the use is non-commercial. See: http:// creativecommons.org/licenses/by-nc/3.0/

\section{REFERENCES}

1. Collin J, LeGresley E, MacKenzie R, et al. Complicity in contraband: British American tobacco and cigarette smuggling in Asia. Tob Control 2004;13:ii104-11.

2. Joossens L, Raw M. Cigarette smuggling in Europe: who really benefits? Tob Control 1998;7:66-71.

3. Joossens L, Raw M. How can cigarette smuggling be reduced? $B M J$ 2000;321:947.

4. Legresley E, Lee K, Muggli ME, et al. British American Tobacco and the 'Insidious Impact of Illicit Trade' in cigarettes across Africa. Tob Control 2008;17:339-46.

5. Luk R, Cohen JE, Ferrence R, et al. Prevalence and correlates of purchasing contraband cigarettes on First Nations reserves in Ontario, Canada. Addiction 2009;104:488-95.

6. Shafey O, Cokkinides V, Cavalcante TM, et al. Case studies in international tobacco surveillance: cigarette smuggling in Brazil. Tob Control 2002;11:215-19.

7. Lindmeier C. New international protocol adopted to combat illicit trade in tobacco products. World Health Organization, 2012. http:// www.who.int/fctc/cop/sessions/new_treaty/en/index.html (accessed 6 Feb 2013)

8. Merriman D. The micro-geography of tax avoidance: evidence from littered cigarette packs in Chicago. Am Econ J 2010;2:61-84.

9. Van der Merwe R. Chapter 11: cigarette trade and the potential for smuggling in South Africa. http://archive.idrc.ca/ritc/SAch11.pdf (accessed 10 May 2012).

10. Woelk G, Mtisi S, Vaughan JP. Prospects for tobacco control in Zimbabwe: a historical perspective. Health Policy 2001;57:179-92.

11. Maponya F. 4 Zim Cigarette 'Smugglers' Appear in Court. Sowetan live. http://www.sowetanlive.co.za/news/2012/04/25/4-zim-cigarettesmugglers-appears-in-court (accessed 15 Jun 2012).

12. O'Toole S. Up in smoke. Rolling Stone South Africa 2012:35-29. http://www.stopillegalcigarettes.co.za/files/pdf/ff67f50bd13fc4297 24a6d5f918bcd06/Rolling_Stone_Feature_April_2012.pdf (accessed 12 May 2012).

13. Zim Cigarette Smugglers Cause Havoc. Newsday 2012. http://www. newsday.co.zw/article/2012-05-11-zim-cigarette-smugglers-causehavoc/ (accessed 17 Jul 2012).

14. Up in smoke: more in SA lighting up illegally. South Africa Press, Online 2012. http://sapressonline.com/ncas/wp-content/uploads/ 2012/05/Business-Day-16-May-12.Up-in-smoke-more-in-SA-lightingup-illegally.htm (accessed 20 May 2012).

15. Illicit trade: what do illegal cigarettes really cost our country? South African British American Tobacco, 2012. http://www.batsa.co.za (accessed 12 May 2012).

16. Lemboe C, Black P. Cigarette taxes and smuggling in South Africa: causes and consequence. Stellenbosch Economic Working Papers 2012:9-13. http://www.ekon.sun.ac.za/wpapers/2012/wp092012/ wp-09-2012.pdf (accessed 6 Feb 2013).

17. Tobacco Products Control Amendment Act, 2008. Government Gazette 2009;523:2-14. http://www.saflii.org/za/legis/num_act/ tpcaa2008351.txt (accessed 6 Feb 2013). 